\title{
Premios Teatro del Mundo en el Rojas 2008-2009
}

Desde hace doce años el Centro Cultural Ricardo Rojas de la Universidad de Buenos Aires entrega los Premios Teatro del Mundo, destinados a distinguir a los teatristas argentinos y extranjeros que trabajan para conectar la actividad teatral argentina con la escena internacional. Integran el Jurado cincuenta críticos e investigadores especializados, miembros del Área de Historia y Teoría Teatral y del Centro de Investigación en Historia y Teoría Teatral del Rojas, quienes ponderan aportes artísticos, estéticos y conceptuales de los trabajos presentados durante la temporada. Este año El premio Homenaje fue para Gastón Breyer y el de Trayectoria para Max Berliner. Fueron destacados especialmente Alfredo Ramos; Mauricio Kartun; Villanueva Cosse y Nicolás Costa, Ariel Dilon, Elena Roger, Emiliano Dionisi y Sebastián Mogordoy; el Circo en Hilos, el encuentro Internacional de Monólogos de La Tigra (Chaco), Circo Fokus Bokus (Grupo Kukla, dir. Antoaneta Madjarova), La Revista Afuera (dir. Yanina Andrea Leonardi y Lorena Verzero); el espectáculo Maneries (idea y dirección: Luis Garay; creación: Florencia Vecino-Luis Garay), Gabriela Aurora Fernández (Tango Turco, La pecadora, Ala de criados, Masked), Juan Benbassat, Juan y Alejandra Farley diseño y realización de títeres (Moc y Poc); Felix Padrón, (Los desórdenes de la carne - dramón de amor); Los Amados (intérpretes de Karabalí, ensueño Leocona); Mariano Arrigoni (Una familia dentro de la nieve); Juan Nadalini (Bizarra, Teatro reunido de Manuel Puig Entropía); Paola Hernández, El teatro de Argentina y Chile. Globalización, resistencia $y$ desencanto (Corregidor); La Red de Fotógrafos de Teatro Comunitario (Muestra La Comunidad en Escena, CCC); Bibiana Grabowsky (actriz de La señora Macbeth, La Pampa): También hubo Menciones Especiales para la Biblioteca Hueney (Zapala, Neuquén); Festival Vamos que Venimos; Festival de Teatro Comunitario y Libertablas. El Premio especial Provincia de Buenos Aires fue para David Cureses. 
La Directora del Rojas, Cecilia Vázquez, en la apertura del concurrido acto señaló que es un placer que esta suceda (la entrega de premios) y apuntó "Nuestra institución tiene 5 años de trayectoria teatral y esto es importante no sólo para la UBA y para el Rojas, sino también para los artistas, el público, la ciudad y el país, por las actividades que se realizan en las provincias." Este es un corolario del trabajo que se realiza en ese año. Y es una prueba que frente a situaciones difíciles no nos rendimos y seguimos trabajando. Este es el mayor reconocimiento para nuestro arte, nuestro teatro que merecen contar con todos los elementos que se necesitan para el trabajo.

Minutos antes de presentar los premios Jorge Dubatti, Coordinador del Área de Teoría Teatral del Rojas, destacar que "Este año agregamos un premio a la Patagonia (a sus manifestaciones teatrales) para el que contamos con un jurado especial y una mención especial para la Provincia de Buenos Aires."

Al subir al escenario Villanueva Cosse dijo que "Este lugar en el que hoy me encuentro es un lugar deseado por mí. Este premio y la razón por la que me lo dan es el súmmum de este año. Este trabajo que me llevó 5 meses es el basamento de lo que es hoy Marat-Sade. Lo dedico a mí mismo y al elenco." Por su parte Mauricio Kartun dijo que "Cuando se le da un premio a un dramaturgo se le da indirectamente un premio al elenco. No puedo menos que compartirlo con el elenco. Nos abocamos a una disciplina, una especie que es difícil de encontrar, la literatura dramática."

\section{Universidad de Buenos Aires}

